\section{Prevalência elevada de hepatite $C$ no distrito de Botafogo, cidade de Bebedouro, interior do Estado de São Paulo, Brasil, 2007}

\author{
High prevalence of hepatitis $C$ in the district of \\ Botafogo, municipality of Bebedouro, São Paulo \\ State, Brazil, 2007
}

\author{
1 Faculdade de Medicina de \\ Ribeirão Preto, Universidade \\ de São Paulo, Ribeirão Preto, \\ Brasil. \\ 2 Instituto Oswaldo Cruz, \\ Fundação Oswaldo Cruz, \\ Rio de Janeiro, Brasil. \\ Correspondência \\ S. B. R. L. Ferrão \\ Departamento de Medicina \\ Social, Faculdade de \\ Medicina de Ribeirão Preto, \\ Universidade de São Paulo. \\ Rua 24 de Maio 859 \\ apto. 301, Jaboticabal, SP \\ 14870-350, Brasil. \\ sabrinaferrao@hotmail.com
}

\begin{abstract}
This article aimed to estimate the prevalence of hepatitis C in Botafogo, a district of Bebedouro, São Paulo State, Brazil, and investigate possible risk factors. One individual over 18 years of age was selected from each household to answer a questionnaire on socio-demographic variables and factors associated with hepatitis C. Blood samples were also drawn for immunoenzymatic tests. Positive HCV-antibody samples were submitted to viral RNA detection. HCV prevalence was 8.8\% (95\%CI: 5.8-11.7), and independent variables associated with risk of infection were: male gender, time of local residence $>30$ years, and history of injected medication using nondisposable material, sterilized by boiling. The high prevalence of hepatitis $C$ infection in this relatively isolated rural population appears to result from previous exposure to injections with inadequately sterilized material, with some evidence suggesting a specific elderly pharmacy employee who customarily applied such injections and may have been a chronic HCV carrier.
\end{abstract}

Hepatitis C; Prevalence; Risk Factors
Sabrina de Brito Ramalho Luz Ferrão 1 José Fernando de Castro Figueiredo 1 Clara Fumiko Tachibana Yoshida 2 Afonso Dinis Costa Passos 1

\section{Introdução}

A disseminação do vírus da hepatite $\mathrm{C}$ deve-se fundamentalmente à exposição parenteral a sangue ou derivados 1 . Outros fatores associados incluem hemodiálise prolongada, exposição sexual, acidentes perfuro-cortantes em profissionais da saúde, contato com comunicante domiciliar e nível sócio-econômico baixo ${ }^{1}$. Diferentes atividades envolvendo contato com sangue, como tatuagens, piercing, acupuntura e rituais religiosos com escarificação também são consideradas fatores associados, embora até o momento não existam estudos concluindo que estas práticas isoladas sejam, de forma consistente, responsáveis pela transmissão 1,2 .

A escassez de trabalhos de base populacional dificulta a análise e interpretação dos fatores associados, uma vez que a maioria dos estudos aborda populações específicas, comprometendo a generalização dos resultados. A presente investigação retrata um estudo populacional realizado em uma comunidade do interior do Estado de São Paulo, Brasil, onde a detecção de um elevado número de infectados chamou a atenção de profissionais da saúde pública e da própria população, a qual passou a demandar o seu esclarecimento. 


\section{Material e métodos}

Botafogo é um distrito do Município de Bebedouro, localizado ao norte do Estado de São Paulo. Sua população estimada para o ano de 2004 era de 1.320 indivíduos e, apesar de se concentrar na sede do distrito, apresenta características predominantemente rurais, com a maioria empregada em atividades agrícolas.

Um mapeamento do Programa Saúde da Família, em 2004, revelava a existência de 374 domicílios, sendo 278 na sede $(74,3 \%)$ e 96 (25,7\%) na área rural. Com exceção de dois, todos foram visitados por uma equipe de saúde. Em cada domicílio foi sorteado um habitante com idade igual ou superior a 18 anos, incluído após assinatura do termo de consentimento livre e esclarecido. Um questionário foi aplicado a cada participante, de quem se coletou uma amostra de $10 \mathrm{~mL}$ de sangue para determinação qualitativa dos anticorpos anti-HCV, sendo utilizado o teste DiaSorin (Kit ETI-AB-HCVK-4, DiaSorin, Madri, Espanha). Os positivos foram confirmados por detecção do RNA viral (PCR qualitativo). Todos os exames foram realizados no Laboratório de Referência Nacional de Hepatites Virais, do Instituto Oswaldo Cruz da Fundação Oswaldo Cruz.

A classificação do estrato sócio-econômico foi realizada segundo o Critério de Classificação Econômica Brasil (Associação Nacional de Empresas de Pesquisa; http://www.anep.org.br, acessado em 25/Abr/2005). As informações foram digitadas em um banco de dados e analisadas através do pacote estatístico Stata 9.0 (Stata Corp., College Station, Estados Unidos). Associações entre a infecção e exposições foram inicialmente exploradas pela aplicação do teste exato de Fisher. As variáveis que mostraram um valor de p igual ou inferior a 25\% foram submetidas à aplicação de um modelo log-binomial.

A pesquisa foi realizada de fevereiro de 2007 a abril de 2008, após aprovação pelo Comitê de Ética em Pesquisa do Hospital das Clínicas da Faculdade de Medicina de Ribeirão Preto da Universidade de São Paulo.

\section{Resultados}

Nas 372 residências visitadas ocorreram 19 recusas $(5,1 \%)$, resultando 353 participantes. A maioria dos domicílios concentrava-se na área urbana, com um predomínio marcante de moradores com situação conjugal estável, categorizados como casados e amasiados (Tabela 1). A amplitude de variação da idade foi de 18 a 94 anos, com média de 46,2 e mediana de 43 anos. Ocorreu predomínio do sexo feminino e do estra- to econômico C, com quase 1/3 dos participantes (30,9\%) tendo idade igual ou superior a 55 anos.

Como visto na Tabela 1, positividade para o vírus da hepatite $C$ foi verificada em 31 participantes, resultando uma prevalência de 8,8\% (IC95\%: 5,8-11,7). Não ocorreu resultado positivo nas idades entre 18 e 35 anos. Em contrapartida, a partir dos 45 anos, verificou-se uma concentração acentuada de infectados, com $13,5 \%$ na faixa de 45 a 55 anos e de 20,2\% naqueles situados acima de 55 anos $(\mathrm{p}<0,001)$. A positividade foi mais elevada entre os homens $(13,1 \%$ contra $5,5 \%$; $p=$ $0,014)$. Os que residiam no distrito há mais de 30 anos mostraram prevalência muito mais elevada do que os habitantes mais recentes $(17,5 \% \mathrm{e}$ 2,0\%; $\mathrm{p}<0,001)$.

A Tabela 2 mostra que a presença da infecção foi 9,7 vezes mais elevada entre os expostos à aplicação de produtos injetáveis com uso de material reutilizável $(13,6 \%$ e 1,4\%; p < 0001).

$\mathrm{Na}$ análise multivariada, as variáveis que se mostraram independentemente associadas à hepatite $\mathrm{C}$ foram: pertencer ao sexo masculino (razão de prevalências = 2,13; IC95\%: 1,09-4,17\%), tempo de residência no distrito acima de 30 anos (razão de prevalências = 5,65; IC95\%: 1,99-16,03) e utilização de medicações parenterais com seringas não descartáveis (razão de prevalências = 5,08; IC95\%: 1,21-21,30). A interação entre a idade e o tempo de residência no local fez com que se preferisse a utilização dessa última variável, apontada pela análise como mais adequada para explicação dos achados.

\section{Discussão}

A identificação de um grande número de casos de hepatite por parte dos habitantes do distrito despertou interesse na presente investigação e contribuiu para que o percentual de recusa ficasse próximo a $5 \%$, reduzindo eventuais vieses de seleção.

A prevalência de 8,8\% é intrigante, uma vez que a taxa mundial é estimada em $3 \%$, e a nacional entre 2,5\% e 4,9\% 1,3. Este valor supera os encontrados nas Américas e Europa e situa-se próximo ao de países africanos e asiáticos 2,4

A relação direta entre a positividade o aumento da idade, com amplo predomínio acima dos 45 anos, corrobora observações realizadas em diferentes partes do mundo 4,5,6, sendo devido, muitas vezes, ao fato de que o passar do tempo tende a acarretar maior probabilidade de exposição a situações de risco.

É possível que características próprias da população de estudo, mormente a sua condição de relativo isolamento e homogeneidade 
Positividade de hepatite C segundo características sociais e demográficas no distrito de Botafogo, Município de Bebedouro, São Paulo, Brasil, 2007

\begin{tabular}{|c|c|c|c|c|c|}
\hline \multirow[t]{3}{*}{ Característica } & \multicolumn{5}{|c|}{ Hepatite C } \\
\hline & \multicolumn{2}{|c|}{ Positivo } & \multicolumn{2}{|c|}{ Negativo } & \multirow{2}{*}{$\begin{array}{l}\text { Valor } \\
\text { de } p\end{array}$} \\
\hline & $\mathbf{n}$ & $\%$ & $\mathbf{n}$ & $\%$ & \\
\hline \multicolumn{6}{|l|}{ Idade (anos) } \\
\hline $18-25$ & - & - & 32 & 100,0 & \\
\hline $25-35$ & - & - & 66 & 100,0 & \\
\hline $35-45$ & 2 & 2,1 & 92 & 97,9 & \\
\hline $45-55$ & 7 & 13,5 & 45 & 86,5 & \\
\hline$>55$ & 22 & 20,2 & 87 & 79,8 & $<0,001$ \\
\hline \multicolumn{6}{|c|}{ Área de residência } \\
\hline Rural & 4 & 4,2 & 92 & 95,8 & \\
\hline Urbana & 27 & 10,5 & 230 & 89,5 & 0,089 \\
\hline \multicolumn{6}{|l|}{ Estado conjugal } \\
\hline Estável & 25 & 9,5 & 239 & 90,5 & \\
\hline Não-estável & 6 & 6,7 & 83 & 93,3 & 0,520 \\
\hline \multicolumn{6}{|l|}{ Sexo } \\
\hline Feminino & 11 & 5,5 & 189 & 94,5 & \\
\hline Masculino & 20 & 13,1 & 133 & 86,9 & 0,014 \\
\hline \multicolumn{6}{|c|}{ Estrato econômico } \\
\hline$A+B$ & 4 & 8,0 & 46 & 92,0 & \\
\hline C & 15 & 7,3 & 190 & 92,7 & \\
\hline$D+E$ & 12 & 12,2 & 86 & 87,7 & 0,356 \\
\hline \multicolumn{6}{|c|}{ Tempo de moradia (anos) } \\
\hline$>30$ & 27 & 17,5 & 127 & 82,5 & \\
\hline$<30$ & 4 & 2,0 & 195 & 98,0 & $<0,001$ \\
\hline Total & 31 & 8,8 & 322 & 91,2 & \\
\hline
\end{tabular}

social, tenham contribuído para a não associação entre a infecção pela hepatite $\mathrm{C}$ e algumas variáveis classicamente mencionadas, tais como relacionamento conjugal instável 1,7 , estrato econômico menos favorecido ${ }^{1}$ e residência em área urbana ${ }^{7}$. A raridade de outros tradicionais fatores associados na população de Botafogo, aí incluídos o uso de drogas ilícitas endovenosas, trabalho na área da saúde, tatuagem, piercing, acupuntura e compartilhamento de escovas de dente, dificulta a tentativa de estabelecimento de associações com a presença de hepatite C. A introdução de testes sorológicos na rotina dos bancos de sangue praticamente eliminou a transmissão de hepatite C por via transfusional, o que justifica a não associação da infecção com antecedente de transfusão de sangue e com procedimentos cirúrgicos.

A constatação de um risco significativamente mais elevado entre os homens confirma observações realizadas em diferentes momentos e populações $1,3,4$, supostamente como resultado de comportamentos de risco mais freqüentes no sexo masculino, como consumo de drogas, multiplicidade de parceiros e exposições a contatos sexuais desprotegidos.

Destaca-se a forte associação entre a infecção pelo vírus da hepatite $\mathrm{C}$ e as variáveis idade, tempo de moradia acima de 30 anos e utilização pregressa de seringas e agulhas reutilizáveis, o que sinaliza a possibilidade de que a disseminação do vírus nessa comunidade tenha se dado há algumas décadas, através de injeções com material contaminado. Uma investigação detalhada revelou que, no passado, os habitantes utilizavam uma farmácia para as suas necessidades de saúde e que o responsável por ela faleceu em decorrência de complicações produzidas por hepatite crônica. Os moradores mais antigos e os parentes próximos do farmacêutico prático têm a firme convicção de que ele padecia de infecção dupla pelos vírus B e C, relatando que esse era também o diagnóstico reconhecido e declarado pelo próprio, com base 


\begin{tabular}{|c|c|c|c|c|c|}
\hline \multirow[t]{3}{*}{ Característica } & \multicolumn{5}{|c|}{ Hepatite C } \\
\hline & \multicolumn{2}{|c|}{ Positivo } & \multicolumn{2}{|c|}{ Negativo } & \multirow{2}{*}{$\begin{array}{l}\text { Valor } \\
\text { de } p\end{array}$} \\
\hline & $\mathrm{n}$ & $\%$ & $\mathrm{n}$ & $\%$ & \\
\hline \multicolumn{6}{|c|}{ Estimulantes parenterais } \\
\hline Sim & - & - & 1 & 100,0 & \\
\hline Não & 31 & 8,8 & 321 & 91,2 & 1,000 \\
\hline \multicolumn{6}{|l|}{ Transfusão de sangue } \\
\hline Sim & 5 & 12,8 & 34 & 87,2 & \\
\hline Não & 26 & 8,3 & 288 & 91,7 & 0,365 \\
\hline \multicolumn{6}{|l|}{ Profissão de risco } \\
\hline Sim & 1 & 11,1 & 8 & 88,9 & \\
\hline Não & 30 & 8,8 & 314 & 91,3 & 0,567 \\
\hline \multicolumn{6}{|l|}{ Tatuagem } \\
\hline Presente & - & - & 7 & 100,0 & \\
\hline Ausente & 31 & 9,0 & 315 & 91,0 & 1,000 \\
\hline \multicolumn{6}{|l|}{ Piercing } \\
\hline Presente & 0 & 0,0 & 2 & 100,0 & \\
\hline Ausente & 31 & 8,8 & 320 & 91,2 & 1,000 \\
\hline \multicolumn{6}{|l|}{ Cirurgias } \\
\hline Sim & 21 & 10,5 & 179 & 89,5 & \\
\hline Não & 10 & 6,5 & 143 & 93,5 & 0,255 \\
\hline \multicolumn{6}{|l|}{ Acupuntura } \\
\hline Sim & 2 & 18,2 & 9 & 81,8 & \\
\hline Não & 29 & 8,5 & 313 & 91,5 & 0,250 \\
\hline \multicolumn{6}{|l|}{ Escovas de dente } \\
\hline Compartilha & - & - & 10 & 100,0 & \\
\hline Não compartilha & 31 & 9,0 & 312 & 91,0 & 1,000 \\
\hline \multicolumn{6}{|c|}{ Injeção com material reutilizável } \\
\hline Sim & 29 & 13,6 & 185 & 86,5 & \\
\hline Não & 2 & 1,4 & 137 & 98,6 & $<0,001$ \\
\hline
\end{tabular}

em informações repassadas pelos médicos que lhe atenderam.

Assim, uma possível explicação para a enorme distribuição viral em indivíduos mais velhos, residentes no local há mais de trinta anos, diz respeito à transmissão por injeções, a partir de uma fonte comum veiculada por instrumental contaminado com o vírus da hepatite $\mathrm{C}$, possivelmente iniciada após algum acidente durante a administração das medicações injetáveis, cuja aplicação em Botafogo era centralizada na figura do farmacêutico. Importante lembrar que esses fatos teriam ocorrido antes da metade da década de 1970, quando a não existência de seringas e agulhas descartáveis obrigava o uso de material reutilizável, que sofria apenas um processo de fervura entre uma utilização e outra.
A disseminação de hepatite $C$ por técnicas inadequadas de esterilização de materiais é reforçada por outros relatos da literatura. Exemplo disso é o Egito, onde prevalências muito elevadas têm sido associadas a tratamento parenteral para esquistossomose ${ }^{4}$. Da mesma forma, descrições de prevalência elevada entre ex-atletas que fizeram uso de estimulantes injetáveis apontam para a relevância desse mecanismo de transmissão em diferentes partes do Brasil 8,9.

Dada a magnitude da situação em Botafogo, além do atendimento aos casos diagnosticados, planeja-se uma investigação que aprofunde o conhecimento da dinâmica local de transmissão e permita identificar outros infectados, propiciando-lhes também adequada atenção médica. 


\section{Resumo}

O objetivo deste artigo foi estimar a prevalência de hepatite C nos moradores de Botafogo, distrito de Bebedouro, São Paulo, Brasil, e estudar possíveis fatores associados. Em cada domicílio foi sorteado um indivíduo com idade mínima de 18 anos, submetido a um questionário que levantava variáveis sócio-demográficas e fatores associados à infecção por hepatite C. Ao mesmo tempo, foi coletada uma amostra de sangue para realização de exames imunoenzimáticos. As amostras positivas ao anti-HCV foram submetidas à detecção do RNA viral. A prevalência de hepatite $C$ encontrada foi 8,8\% (IC95\%: 5,8-11,7) e as variáveis preditoras independentes para o risco de infecção foram: sexo masculino, tempo de residência no local superior a trinta anos e uso de medicações parenterais com material não descartável, esterilizado com técnica de fervura. A prevalência elevada de infecção pela hepatite C nessa população relativamente isolada, de características rurais, parece ser resultado de exposições pregressas a injeções com material não adequadamente esterilizado, com algumas evidências apontando para a possibilidade de envolvimento de um antigo farmacêutico prático, que centralizava a aplicação desses produtose era possivelmente um portador crônico da infecção.

Hepatite C; Prevalência; Fatores de Risco

\section{Colaboradores}

S. B. R. L. Ferrão participou da concepção, projeto, análise, interpretação dos dados e redação do artigo. J. F. C. Figueiredo participou do projeto, análise dos dados e revisão crítica do conteúdo intelectual. C. F. T. Yoshida participou da interpretação dos dados e revisão crítica do conteúdo intelectual. A. D. C. Passos participou do projeto, análise, interpretação dos dados, revisão crítica do conteúdo intelectual e aprovação final da versão a ser publicada.

\section{Referências}

1. Centers for Disease Control and Prevention. Recommendations for prevention and control of hepatitis $\mathrm{C}$ virus (HCV) infection and HCV-related chronic disease. MMWR Recomm Rep 1998; 47(RR-19):1-39.

2. Alter MJ. Epidemiology of hepatitis C virus infection. World J Gastroenterol 2007; 13:2436-41.

3. Brandão ABM, Fuchs SC. Risk factors for hepatitis $\mathrm{C}$ virus infection among blood donors in Southern Brazil: a case-control study. BMC Gastroenterol 2002; 2:18-26.

4. Abdel-Aziz A, Habib M, Mohamed MK, Abdel-Hamid M, Gamil F, Madkour S, et al. Hepatitis C virus (HCV) infection in a community in the Nile Delta: population description and HCV prevalence. Hepatology 2000; 32:111-5.

5. Domingués A, Bruguera M, Vidal J, Plans P, Salleras L. Community-based seroepidemiological survey of HCV infection in Catalonia, Spain. J Med Virol 2001; 65:688-93.
6. Focaccia R, Conceição OJG, Sette Jr. H, Sabino E, Bassit L, Nitrini DR, et al. Estimate prevalence of viral hepatitis in the general population of the municipality of São Paulo, measured by serologic survey of a stratified, randomized and residencebased population. Braz J Infect Dis 1998; 2:269-84.

7. Krawitt EL. Chronic viral hepatitis. In: Mandell GL, Bennett MD, Dolin R, editors. Principles and practice of infectious disease. New York: Churchill Livingstone; 1995. p. 1153-9.

8. Parana R, Lyra LGC, Trepo C. Intravenous vitamin complexes used in sporting activities and transmission of HCV en Brazil. Am J Gastroenterol 1999; 94:857-8.

9. Souto FJD, Silva AG, Yonamine F. Risk of hepatitis $\mathrm{C}$ among Brazilian ex-soccer players. Mem Inst Oswaldo Cruz 2003; 98:1025-6.

Recebido em 30/Jun/2008

Versão final reapresentada em 22/Out/2008 Aprovado em 24/Out/2008 